\title{
Pengelolaan Media Sosial pada Usaha XYZ
}

\author{
Nuraini Arifianti*, Nunuk Adiarni*
}

\begin{abstract}
ABSTRAK
Penelitian ini dilakukan untuk mengetahui bagaimana pengelolaan media sosial pada usaha XYZ. Media sosial saat ini tidak saja sebatas menjalin hubungan pertemanan, tetapi dimanfaatkan untuk keperluan bisnis. Masyarakat mengenal media sosial diantaranya, Line, Whatshapp, Instagram, Facebook. Terkait dengan tujuan bisnis, konten (content), yang atraktif dimungkinkan dengan tersedianya aplikasi yang mampu menyampaikan pesan pemasaran kepada konsumennya. Namun, pengelola perlu kontinu mengelolanya agar sesuai sasaran. Hal ini membutuhkan content dan message creator yang kreatif, yang bekerjasama dengan decision maker dan administrator. $X Y Z$ dalam memanfaatkan media sosial memilih instagram untuk kegiatan pemasaran bisnisnya. Penelitian ini menggunakan metode deskriptif kualitatif dan hasil penelitian menunjukkan bahwa Pengelolaan Instagram yang diterapkan XYZ dimulai dari pemilihan target konsumen sampai dengan proses evaluasi konten. Namun, belum secara komprehensif terkecuali penanganan komentar negatif dari followers. Hasil penelitian membuktikan pemanfaatan media sosial seperti Instagram dalam melakukan pemasaran memerlukan pengelolaan. Tahapan perencanaan konten, pengorganisasian dan proses pengambilan keputusan merupakan kerja tim, dilanjutkan dengan evaluasi dan merespon tanggapan follower.
\end{abstract}

Kata kunci: Media sosial, Instagram, pengelolaan media sosial.

\section{ABSTRACT}

The social media is currently not only used for social friendship but also for business purpose.The people use line, whatshapp, instagram and facebook. Related to business goals, the content is made possible by availability of the applications to convey marketing messages to customers. This requires creative message and content creators, which work in team with decision maker and administrator. However, it's need to continuously manage it. This study was aimed to find out how the management of social media in XYZ businesses using descriptive qualitative. Instagram management implemented by XYZ starts from setting target customers to the content evaluation process. However, it has not comprehensively been managed unless it responds to negative comments from followers. The results of the study prove that using the social media such as Instagram in marketing requires management by planning, organizing and decision making process for creative content and followed by an evaluation and handling follower responses.

Keywords: social media, Instagram, management of social media.

\section{PENDAHULUAN}

Media sosial merupakan salah satu platform di era digital yang paling digemari, dan merupakan media yang digunakan untuk bersosialisasi melalui jaringan internet. Media sosial adalah fitur berbasis website yang dapat membentuk jaringan serta memungkinkan orang untuk berinteraksi dalam sebuah komunitas (Puntoadi, 2011:1). Berdasarkan hasil survei Asosiasi Penyelenggara Jasa Internet Indonesia (APJII) tahun 2017 menyatakan bahwa sebanyak 87,13\% layanan yang diakses masyarakat adalah media sosial. Berdasarkan data Wearesocial.com yang dikutip oleh Ariyanti tahun 2018, pada Industri Bisnis 
tahun 2018, menyatakan Indonesia memiliki 130 juta pengguna media sosial aktif. Pernyataan Direktur Jenderal Aplikasi dan Informatika Samuel A. Pangerapan, yang dikutip oleh Agung pada CNN Indonesia tahun 2017, menyatakan bahwa rata-rata masyarakat Indonesia menghabiskan \pm 3 jam 15 menit untuk mengakses media sosial.

Menurut survei yang dilakukan Asosisasi Penyelenggara Jasa Internet Indonesia (APJII) pada tahun 2017, mayoritas pengguna internet di Indonesia merupakan masyarakat dengan kelompok usia 19-34 tahun atau sebesar 49,52\%. Kemudian, pada urutan kedua terdapat usia 35-54 tahun atau sebesar 29, 55\%, urutan ketiga adalah usia 13-18 tahun atau sebesar $16,68 \%$ dan pengguna dengan usia di atas 54 tahun atau sebesar $4,24 \%$. dimana media sosial menjadi konten yang paling sering diakses (Katadata, 2018).

Media sosial yang pada awalnya hanya berfungsi sebagai situs pertemanan dan pertukaran informasi sesama teman atau kerabat dekat, saat ini telah beralih fungsi sebagai lahan pemasaran suatu perusahaan maupun toko online dalam skala industri rumahan. Saat ini media sosial telah menjadi wadah untuk melakukan kegiatan berbelanja secara online (Mulawarman dan Nurfitri, 2017:41). Kegiatan berbelanja secara online yang memanfaatkan media sosial disebut dengan social media marketing.

Menurut Genelius (2011:10) social media marketing adalah suatu bentuk pemasaran langsung maupun tidak langsung yang digunakan untuk membangun kesadaran, pengakuan, daya ingat, dan tindakan untuk merek, bisnis, produk, orang, atau entitas lainnya yang dilakukan dengan menggunakan alat dari web sosial. Tujuan umum dari pemasaran media sosial adalah membangun hubungan, membangun merek, publisitas, promosi, dan riset pasar.

Perkembangan media sosial telah berdampak pada cara berkomunikasi perusahaan. Munculnya web 2.0 bahkan web
3.0 telah mendorong perusahaan untuk berbagi informasi secara lebih terbuka dengan pelanggannya, sehingga berkembanglah pemahaman mengenai pentingnya social media marketing (Priansa, 2017:357). Social media marketing adalah bentuk pemasaran langsung atau tidak langsung yang digunakan untuk membangun kesadaran, pengakuan, ingat dan tindakan untuk merek, bisnis, produk, orang atau badan lain dan digunakan menggunakan alatalat dari web sosial, seperti blogging, mikrobloging, jejaring sosial, bookmark sosial, dan konten. Social media marketing menawarkan kesempatan besar untuk pengusaha, usaha kecil, perusahaan menengah, dan perusahaan besar untuk membangun merek dan bisnis mereka (Genelius, 2011:10).

Di dalam penggunaan media sosial untuk pemasaran, seluruh interaksi dan perubahan sistem informasi terbaru yang terus menerus harus dikendalikan, direncanakan, dikelola untuk mendapatkan hasil yang optimal. Secara teori seperti yang dikemukakan Paramitha (2011) dalam Pakuningjati (2015:10), pengelolaan media sosial secara teknis yang terpenting pada dasarnya adalah mengatur perencanaan, aktivasi dan pengawasan serta optimalisasi. Pemasaran produk melalui media sosial merupakan tantangan tersendiri, karena calon konsumen tidak melihat secara langsung kondisi fisik produk, oleh sebab itu diperlukan adanya pengelolaan dalam melakukan pemasaran melalui media sosial.

Salah satu unit usaha yang menggunakan media sosial untuk memasarkan produknya adalah usaha XYZ. XYZ adalah usaha yang bergerak di bidang agribisnis pada subsistem hilir, yaitu pemasaran madu. Produk-produk yang dijual XYZ adalah Sarang Madu Melifera dan Cerana, Madu Peras Melifera, Cerana dan Kaliandra serta Masker Madu. XYZ hanya melakukan pemasaran dengan menggunakan media sosial. Media sosial yang digunakan XYZ adalah Facebook, 
Twitter, Youtube dan Instagram, namun yang paling aktif saat ini adalah Instagram. Walaupun memiliki pengikut yang banyak di Instagram dibandingkan dengan pesaing, yaitu 93.600 akun (per Agustus 2018) dan pemasarannya sudah mencakup hampir seluruh wilayah di Indonesia, terdapat beberapa masalah yang dihadapi XYZ. Masalah-masalah tersebut yaitu, munculnya banyak pesaing, dan ditemui beberapa diantaranya mengambil dan menggunakan konten (gambar atau video) XYZ tanpa izin. Diakui terdapat tantangan dalam membuat konten (gambar atau video) dan interaksi dengan pengikut (followers). Kesulitan dalam membuat konten karena pembuatan konten tergantung kepada satu orang content creator. Pembuatan konten harus menarik, tidak monoton, dan selalu menyesuaikan dengan perkembangan trend (up to date).

Permasalahan yang terjadi pada usaha XYZ adalah adanya rangkap jabatan, yaitu content creator juga bertugas sebagai admin Instagram. Hal tersebut menyebabkan content creator sekaligus admin Instagram XXX menjadi kewalahan, selain berpikir ide baru untuk penggantian tema konten agar konsumen tidak merasa bosan, juga mengadministrasikan lintas informasi. Berdasarkan fenomena yang telah diuraikan dan permasalahan pada XYZ, maka penelitian ini bertujuan untuk mengetahui pengelolaan media sosial di XYZ.

\section{Rumusan Masalah}

Berdasarkan uraian pada latar belakang, maka dapat dirumuskan permasalahan, yaitu bagaimana pengelolaan media sosial pada usaha XYZ?

\section{METODE PENELITIAN Waktu dan Lokasi Penelitian}

Penelitian ini dilakukan pada usaha PIRT XYZ, yang berlokasi di Cikarang Bekasi, Jawa Barat. Penelitian dilakukan kurang lebih selama satu bulan, yaitu bulan Oktober 2019.

\section{Jenis dan Sumber Data}

Jenis data pada penelitian ini adalah kualitatif. Data kualitatif berupa data profil usaha XYZ dan sinformasi mengenai pengelolaan media sosial. Sumber data primer diperoleh melalui observasi dan wawancara mengenai usaha dan pengelolaan media sosial di P-IRT XYZ. Data sekunder diperoleh dari kajian pustaka yang diambil melalui literatur dari buku, website, jurnal ilmiah, skripsi dan tulisan lain yang berkaitan dengan penelitian ini.

\section{Metode Pengumpulan Data}

Pengumpulan data dilakukan dengan metode wawancara, observasi, dan studi pustaka. Wawancara dilakukan dengan pemilik usaha serta tiga orang pegawai lainnya yang terkait dengan media sosial. Observasi dilakukan pada pembuatan konten dan handling order. Pada penelitian ini studi pustaka dilakukan dengan mencari literatur mengenai media sosial, dan pengelolaan media sosial.

\section{Metode Pengolahan Data dan Analisis Data}

Data kualitatif yang didapatkan dari hasil wawancara dan observasi, selanjutnya diolah oleh peneliti dengan metode triangulasi yang hasilnya berupa pemetaan pengelolaan media sosial Instagram XYZ. Triangulasi pada penelitian ini digunakan untuk pengecekan kebenaran atau keandalan instrument (Arikunto, 2018:255).

Analisis data yang digunakan pada penelitian ini adalah analisis deskriptif. Deskriptif kualitatif adalah rangkaian kegiatan yang dilakukan untuk memperoleh data berdasarkan fakta. Kegiatan analisis deskriptif kualitatif pada penelitian ini meliputi pengumpulan data dari hasil wawancara dan observasi, kemudian peneliti lakukan analisis data-data tersebut dengan metode triangulasi.

Triangulasi adalah pengecekan kebenaran atau informasi yang diperoleh 
peneliti dari berbagai sudut pandang (informan) yang berbeda untuk mengurangi bias yang terjadi pada saat pengumpulan dan analisis data. Pada penelitian ini teknik triangulasi yang digunakan adalah triangulasi data, triangulasi teori, triangulasi peneliti dan triangulasi metodologi.

\section{HASIL DAN PEMBAHASAN Pengelolaan Media Sosial Usaha XYZ}

Proses pengelolaan media sosial XYZ dimulai dari perencanaan, aktivasi dan pengawasan serta optimaliasi yang sesuai dengan teori Paramitha (2011) dalam Pakuningjati (2015:10). Berikut adalah rincian proses pengelolaan media sosial XYZ.

\section{Perencanaan}

Usaha XYZ melakukan perencanaan dimulai dari pemilihan strategi komunikasi pemasaran melalui media sosial karena pola interaksi masyarakat saat ini yang lebih sering menggunakan media sosial untuk berkomunikasi.

Pada proses perencanaan, usaha XYZ juga menentukan siapa yang akan menjadi target konsumen. Target konsumen yang dipilih adalah generasi millennial (generasi yang lahir pada tahun 1980-2000) yang menggunakan media sosial. Pemilihan generasi millennial sebagai target konsumen mempengaruhi bentuk media sosial yang akan digunakan, konten yang akan dibangun dan informasi yang akan usaha XYZ sampaikan.

Pemilik usaha XYZ melakukan pengamatan terlebih dahulu mengenai media sosial yang paling banyak digunakan, seperti Facebook, Twitter dan Instagram. Berdasarkan pengamatan tersebut media sosial yang terpilih dan cocok untuk pemasaran adalah Instagram. Konten yang dibangun dan informasi yang akan disampaikan $\mathrm{XYZ}$ di Instagram menyesuaikan dengan trend dan karakteristik pengguna media sosial Instagram. Bagan yang memperjelas proses perencanaan media sosial Instagram XYZ merujuk pada Gambar 1.

\section{Aktivasi dan Pengawasan}

Pada tahap ini usaha XYZ menentukan informasi yang akan disampaikan dan menentukan konten pembeda apa yang membedakannya dari usaha sejenis yang melakukan pemasaran melalui media sosial Instagram. Informasi yang disampaikan XYZ terdiri dari informasi produk, cara pemesanan, manfaat madu, resep minuman atau masakan dari madu, jenis-jenis madu, peristiwa yang sedang terjadi dan dikaitkan dengan produk madu, serta ajakan mendonasikan bantuan untuk korban bencana melalui XYZ.

Konten yang menjadi pembeda antara $\mathrm{XYZ}$ dengan usaha lain sejenis yang menggunakan Instagram adalah selalu menyisipkan logo di setiap unggahannya, identik dengan warna kuning, dan setiap tiga bulan berganti tema. Tema dan konten $\mathrm{XYZ}$ dibuat oleh seorang content creator, yaitu DR.

Pergantian tema konten berdasarkan ketajaman content creator dalam menangkap peristiwa, trend atau event yang terjadi, yang kemudian dikaitkan dengan produk XYZ. Berbeda dengan tema, munculnya ide pembuatan konten berasal dari Pinterest, karena menurut content creator pada Pinterest terdapat banyak gambar yang menginspirasinya.

Konten yang akan dibuat menyesuaikan dengan tema yang berasal dari peristiwa, trend atau event yang terjadi. Hal pertama yang harus dilakukan dalam pembuatan konten adalah menentukan tema kemudian membuat konten (gambar atau video) yang sesuai. Pada satu tema, content creator membuat beberapa konten (gambar atau video) yang kemudian diberikan kepada WA sebagai decision maker untuk dinilai. Dari beberapa konten yang dibuat oleh content creator tidak semua akan diunggah di Instagram. Konten yang akan diunggah adalah konten yang menurut penilaian 
decision maker bagus, menarik dan sesuai dengan pesan yang akan disampaikan bersama dengan gambar atau video.

Proses selanjutnya yang masih termasuk dalam tahap aktivasi dan pengawasan adalah cara tim mengelola dan menempatkan pesan-pesan ke dalam media sosial. Sebelum mengunggah konten yang berisi pesan di Instagram, message creator XYZ, yaitu WA membuat pesan yang kemudian didiskusikan dengan decision maker yaitu DR. Inspirasi pembuatan message berasal dari ide WA yang banyak didapatkan dari hasil membaca pesan pada iklan pemasaran di berbagai media.

Fitur Instagram yang digunakan untuk menyampaikan pesan adalah insta story dan unggah foto. Pesan merupakan rangkaian kata yang menjadi informasi dan disertai gambar atau video. Insta story digunakan untuk membagikan ulasan yang diberikan konsumen, interaksi tanya jawab, dan informasi ketersediaan sarang madu dan madu peras. Fitur unggah foto digunakan untuk membagikan pesan yang berisi informasi produk, cara pemesanan, dan lainlain.

Dibalik konten (gambar atau video) XYZ yang menarik, terdapat kerjasama antara DR sebagai content creator dan WA sebagai message creator. Selain menjadi content creator dan message creator, keduanya juga merupakan decision maker. Mereka bekerjasama untuk mensinergikan antara konten dan pesan agar menarik dan mudah dipahami oleh calon konsumen. Proses kerjasama dimulai ketika message creator membuat konsep dasar pesan yang akan disampaikan ke calon konsumen. Kemudian konsep tersebut dibahas bersama decision maker yaitu DR, sehingga menghasilkan pesan akhir yang akan diunggah.

DR sebagai content creator bertugas merealisasikan pesan tersebut kedalam gambar atau video yang sesuai dengan pesan. Sebelum diunggah ke Instagram $\mathrm{XYZ}$, hasil rancangan gambar atau video tersebut ditinjau kembali oleh WA sebagai decision maker. Hasil tinjauan berupa saran akan dipertimbangkan oleh DR untuk melakukan pengeditan gambar atau video sebelum diunggah. Jika dirasa sudah sesuai dengan konsep pesan maka gambar atau video tersebut diunggah di Instagram XYZ. Bagan yang memperjelas proses aktivasi dan pengawasan media sosial Instagram XYZ merujuk pada Gambar 1.

\section{Optimalisasi}

Tahap akhir pengelolaan media sosial adalah optimalisasi. Pada proses ini dilakukan evaluasi konten. Evaluasi ini dilakukan oleh pemilik usaha XYZ dan admin Instagram, yaitu WA dan DR. Berdasarkan hasil wawancara, hasil evaluasi konten sampai saat ini dapat dikatakan sesuai harapan kedua evaluator. Pada umumnya, proses untuk evaluasi agar dapat terukur, digunakan SEO (Search Engine Optimization), namun XYZ tidak menggunakan SEO, karena beresiko tinggi terhadap reputasi XYZ. Bagan yang memperjelas proses optimalisasi media sosial Instagram XYZ merujuk pada Gambar 1.

\section{Pemetaan Pengelolaan Media Sosial Instagram XYZ}

Penerapan pengelolaan media sosial Instagram XYZ yang diperoleh dari metode wawancara dan observasi, dirangkum menjadi sebuah bagan yang tersaji pada Gambar 1. Pengelolaan media sosial XYZ dilakukan oleh tim yang terdiri dari empat orang, yaitu WA, DR, AL, dan NA. Keempat orang tersebut masing-masing memiliki tugasnya dalam melakukan pemasaran produk XYZ melalui media sosial. Berdasarkan hasil wawancara dan observasi, menghasilkan output berupa pemetaan media sosial Instagram XYZ sebagai berikut. 


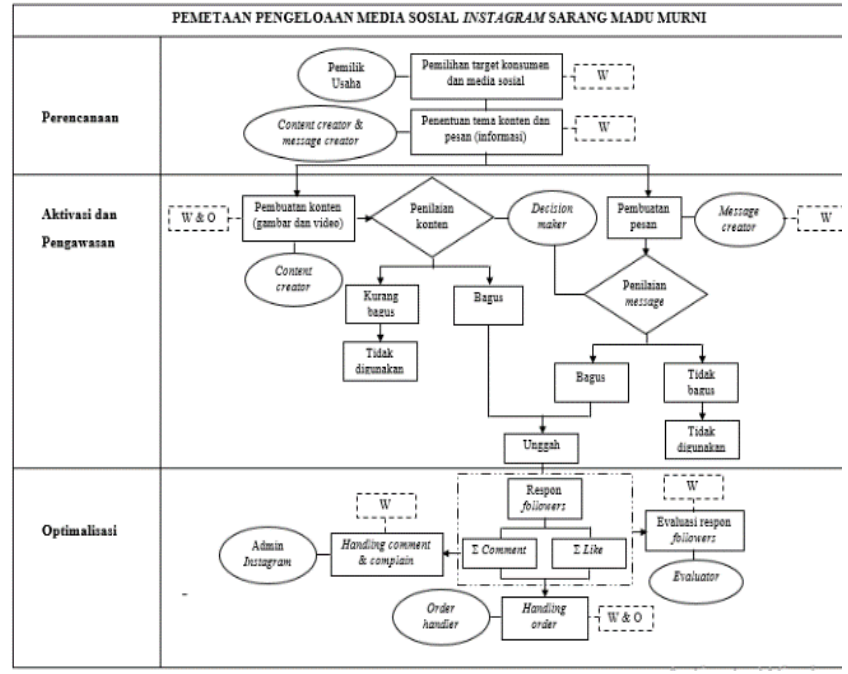

Gambar 1. Pemetaan Pengelolaan Media Sosial Instagram XYZ

Berdasarkan Gambar 1, pemetaan pengelolaan media sosial Instagram $\mathrm{XYZ}$ dimulai dari pemilihan target konsumen dan media sosial yang akan digunakan. Target konsumen yang dipilih XYZ adalah generasi milenial, dan pemilik XYZ menetapkan Instagram sebagai media sosial yang aktif digunakan. Tahap selanjutnya dalam perencanaan adalah penentuan tema konten dan pesan (informasi) yang akan disampaikan. Pada proses aktivasi dan pengawasan dimulai dari pembuatan konten (gambar atau video) dan pembuatan message. Pembuatan konten dilakukan oleh content creator, yaitu DR. Konten dibuat semenarik mungkin agar tidak membosankan dan sesuai dengan pesan yang akan disampaikan. Penilaian konten dilakukan oleh WA sebagai decision maker.

Supaya konten tidak monoton, content creator selalu mencari referensi gambar dari berbagai macam sumber seperti Pinterest. Content creator dibantu oleh seorang photographer bayaran untuk pengambilan foto atau video. Hasil foto atau video photographer selanjutnya diedit oleh content creator dengan menggunakan aplikasi agar sesuai dengan yang diinginkan content creator.

Setelah konten selesai dibuat, kemudian dilakukan penilaian oleh decision maker, yaitu WA. Jika konten tersebut dinilai kurang bagus dan tidak sesuai dengan pesan maka tidak digunakan, namun jika konten tersebut dinilai bagus dan sesuai dengan pesan, maka akan diunggah di Instagram. Pembuatan message dilakukan oleh message creator, yaitu WA. Sebelum membuat message, WA mencari referensi kata-kata yang menarik dari berbagai iklan produk di sekitarnya.

Setelah message selesai dibuat, dilakukan penilaian oleh decision maker. Jika message tersebut dinilai kurang bagus maka tidak digunakan, namun jika message dinilai bagus maka akan diunggah di Instagram. Setelah konten dan message diunggah di Instagram, kemudian dilihat respon dari pengikut Instagram XYZ. Respon tersebut berupa jumlah like dan komentar pada Instagram XYZ. Hasil respon followers berupa like dan komentar pada Instagram dievaluasi oleh dua evaluator, yaitu WA dan DR. Evaluasi tersebut berupa seberapa banyak like yang didapat dan respon calon konsumen pada kolom komentar.

Rata-rata XYZ mendapatkan seribu like pada setiap unggahan kontennya. Jika jumlah like yang didapat kurang dari seribu, maka akan dievaluasi, apakah konten atau message yang diunggah kurang menarik atau monoton. Jika pada kolom komentar terdapat komentar atau ulasan negatif maka akan dievaluasi mengapa ada follower yang memberikan komentar atau ulasan negatif tersebut. Jika respon yang diberikan follower baik, maka tidak dilakukan evaluasi.

Kolom komentar berisi pertanyaan dan complain dari followers Instagram XYZ. Komentar-komentar tersebut ditangani oleh admin Instagram. Setiap ada komentar yang masuk, sebisa mungkin langsung dibalas oleh admin Instagram. Followers yang ingin membeli produk juga dapat menanyakan persediaan dan cara pemesanan melalui kolom komentar.

Calon konsumen yang akan membeli produk, akan diarahkan untuk melakukan pemasanan melalui Whatsapp atau Line XYZ. 
Handling order dilakukan oleh dua order handler, yaitu AL dan NA. Handling order melalui Line ditangani oleh AL, sedangkan handling order melalui Whatsapp ditangani oleh NA. Setelah kedua order handler tersebut menerima pesanan melalui Line dan Whatsapp, kemudian mereka melakukan pencatatan pemesanan secara manual pada buku.

\section{KESIMPULAN}

Berdasarkan hasil penelitian didapatkan kesimpulan yaitu, pengelolaan media sosial Instagram yang diterapkan usaha XYZ yang sesuai dengan teori perencanaan, aktivasi dan pengawasan, dan optimalisasi dimulai dari pemilihan target konsumen sampai dengan proses evaluasi konten, yang hanya dilakukan ketika terdapat komentar negatif dari followers. Hal tersebut membuktikan bahwa dalam melakukan pemasaran melalui media sosial diperlukan pengelolaan, agar usaha tersebut dapat terus bertahan dan berkembang.

\section{DAFTAR PUSTAKA}

Agung, Bintoro. 2017. Penguna Internet di Indonesia Akses Medsos 3 Jam per Hari. Diperoleh dari https: //www.cnnindonesia.com/teknologi/20 171218192500-192-263281/penggunainternet-di-indonesia-akses-medsos-3jam-per-hari. Diakses pada 17 Juli 2018.

Arikunto, Suharsimi. 2018. Prosedur Penelitian Suatu Pendekatan Praktik. Rineka Cipta: Jakarta.

Ariyanti, Duwi Setiya. 2018. Separuh Populasi Indonesia Aktif di Medsos. Diperoleh dari http: //industri.bisnis.com/read/20180131/10 5/732548/130-juta-penduduk- indonesia-pengguna-media-sosial.

Diakses pada 17 Juli 2018.

Asosiasi Penyelenggara Jasa Internet Indonesia (APJII). 2017. Infografis Penetrasi \& Perilaku Pengguna Internet Indonesia. Asosiasi Penyelenggara Jasa Internet Indonesia: Jakarta.

Genelius, Susan. 2011. 30-Minute Social Media Marketing. United States: McGraw-Hill Companies.

Katadata. 2018. Data Media Sosial yang Paling Sering digunakan Di Indonesia: https://databoks.katadata.co.id/datapub lish/2 018/02/01/media-sosial-apayang-palingsering-digunakanmasyarakat-indonesia. Diakses pada 11 Des 2018.

Mulawarman dan Aldila Dyas Nurfitri. 2017. Perilaku Pengguna Media Sosial beserta Implikasinya Ditinjau dari Perspektif Psikologi Sosial Terapan. Buletin Psikologi Vol. 25 No. 1, 36-44. Universitas Gadjah Mada. Yogyakarta.

Pakuningjati, Anindita Lintang. 2015. Penglolaan Media Sosial dalam Mewujudkan Good Governance (Studi Kasus Pengelolaan Media Sosial LAPOR! Sebagai Sarana Aspirasi dan Pengaduan Rakyat secara Online oleh Deputi I Kantor Staf Presiden) [Skripsi] Fakultas Ilmu Sosial dan Politik Universitas Gadjah Mada. Yogyakarta.

Priansa, Donni Juni. 2017. Komunikasi Pemasaran Terpadu pada era media sosial. CV. Pustaka Setia: Bandung

Puntoadi, Danis. 2011. Menciptakan Penjualan Melalui Sosial Media. Jakarta: PT Eles Komputindo.

*Dosen di UIN Syarif Hidyatullah Jakarta

(Email: adiarnisunarjo@gmail.com) 